\title{
SUPPLY-SIDE REFORMS AND LEARNING DYNAMICS
}

\author{
Chryssi Giannitsarou* ${ }^{* \dagger}$ \\ Revised, February 2003
}

\begin{abstract}
This paper studies the nature, the magnitude and the length of the transition after a capital tax cut. The transition is analysed with adaptive learning, under which agents do not need to adjust instantaneously to the change, as with rational expectations (RE). Impulse response analysis reveals that the transition with learning is asymmetrically sensitive to the nature of the exogenous technological shock at the time of the reform. If the reform coincides with a negative shock, the transition to the new steady state is slow, whereas, if it coincides with a positive shock, it is approximately the same as the one predicted by RE. The results imply that cutting capital income taxes before or during a recession may not be an effective means for short-run fiscal stimulus.
\end{abstract}

JEL Classification: D83, E62, H30

KEYWORDS: Supply-side reforms, transition dynamics, adaptive learning

\section{INTRODUCTION}

There is by now a large literature arguing in favour of low tax rates on capital. In the neoclassical growth model, the optimal long-run tax rate on capital is zero if the economy is non-stochastic and approximately zero if the economy is stochastic. In practice, supply-side reforms are designed to boost incentives to invest. ${ }^{1}$ Nevertheless, experience suggests that such reforms take a long time to bring about the desired effects. Recently, the set of tax cuts introduced in the US in order to halt the growth decline of the economy, ignited a heated debate on the appropriateness of the timing of the reform. Some believe that the tax cuts will help the economy escape an imminent recession. Glenn Hubbard, chairman of the Council of Economic Advisers of the Bush administration, believes that "the terrorist attack [...] acted as an adverse 'supply shock' to the economy. [...] The economy would benefit from timely implementation of [the tax cuts]." 2 G. W. Bush states that "If you want to get your way out of recession, you provide tax relief." 3 Others are rather sceptical about the immediate effects of the reform. Richard Curtin, director of the University of Michigan's Surveys of Consumers, believes that "when you do cut taxes by substantial amounts, [...] some of it

\footnotetext{
* Correspondence: Universidade Nova de Lisboa, Faculdade de Economia, Travessa Estêvão Pinto, Campus de Campolide, PT-1099-032 Lisboa, Portugal. E-mail: cgiannitsarou@fe.unl.pt. Tel: +351 2138016 00. Fax: +351 213886073 . Web: http://www.fe.unl.pt/ ${ }^{\sim}$ chryssi

${ }^{\dagger}$ I am grateful to Andrew Scott and Albert Marcet for extensive discussions and feedback on this project. For comments and suggestions, I thank Seppo Honkapohja, Flavio Toxvaerd, John Driffill, Eva CarcelesPoveda, an anonymous referee, as well as seminar participants at London Business School, Universidade Nova de Lisboa, University of California Santa Barbara, Universitat Pompeu Fabra, and Université du Québec à Montréal.

${ }^{1}$ The term 'supply-side economics', as a reference to a cut in capital taxes, is borrowed from the seminal lecture of Lucas (1990).

${ }^{2}$ The Stimulus the Economy Needs, commentary, Wall Street Journal, 25/10/2001.

${ }^{3}$ Speech in Ontario, California, 5/1/2002. Source, BBC.
} 
will help the economy, but the timing of that help will be rather slow and the pace rather sluggish [and] will prove to be a less effective means of stimulating the economy than they might have hoped." 4 At the other end, Senate Majority Leader Tom Daschle recently stated that "Not only did the tax cut fail to prevent recession, [...] it probably made the recession worse." 5

The lack of clear-cut answers to the issues related to the short-run effects of tax cuts suggests that there is a need for a better understanding of the transition dynamics. This paper examines three key issues related to a cut of capital tax rates: (a) the nature and the magnitude of the short-run effects of such a reform, (b) the length of the transition period and (c) the appropriate timing for such a reform. The novelty of the present work is that it addresses these issues, by employing a hypothesis for analysing transitional dynamics alternative to rational expectations (RE), namely adaptive learning.

One of the arguments in favour of $\mathrm{RE}$ is that a plausible learning/adaptive process will ensure convergence to the rational expectations equilibrium (REE), i.e. that economic agents eventually learn to form rational expectations. However, this argument is delicate for analysing transition dynamics that come after policy changes, or, in general, any kind of large structural shifts. This is because, in the early periods, the agents have no or very little information on the effects of such changes. Arguably, adaptive learning provides a more plausible approximation of an economy in transition than RE. The adjustment of the expectations formation takes place gradually, based on reasonable estimates derived from the new information received after the reform is implemented.

The analysis consists of studying the effects of an unanticipated and permanent elimination of capital income taxation in two economies that are identical in all respects, apart from the way the agents form expectations about future variables. The first economy consists of agents that are rational. The second economy consists of agents that can be viewed as econometricians who form expectations using least squares estimates. I will refer to these agents as learners. The model describing the economies follows the standard lines of the real business cycle framework and it ensures that the focus remains on the comparison of the transitions with RE and adaptive learning.

I find that under adaptive learning, the transition can be significantly different from the one predicted by RE. The differences between the transitions are related to the timing of the tax reform. Impulse response analysis under adaptive learning reveals that: (a) the nature and the magnitude of the short-run effects depend on the exogenous technological shock at the time when the reform is implemented and on the state of the economy prior to the reform. Specifically, when the reform coincides with a negative shock and/or a low level of capital stock, production falls below the pre-reform steady state for a long time before it starts growing towards the higher post-reform steady state (while RE predicts an immediate increase). If, however, it coincides with a positive shock, the transition with learning is approximately the same as the one predicted by RE. (b) The speeds of convergence to the post-reform steady state also depend on the initial realisation of the technological shock and on the pre-reform state of the economy. When the shock is negative, adjustment is significantly slower under learning than under RE. This effect is magnified if the capital stock

\footnotetext{
${ }^{4}$ Interview for BBC's World Business Report, 5/10/2001.

${ }^{5}$ Speech, 4/1/2002. Source, CNN.
} 
at the time of the reform is below its original steady state level. As the shock increases, the impulses for both economies converge to the new steady state with approximately the same speed.

The findings have a simple intuition. When agents learn, their expectations about future returns on investment, and hence their decisions about consumption, are only based on the limited information they presently have. Therefore, a series of negative shocks prevents the agents from interpreting the effects of the reform as a change towards a higher steady state. If, however, the agents are rational, they realise immediately after the reform that the new tax rates imply higher future returns, whatever shocks the economy is subjected to. Their expectations and their consumption decisions adjust accordingly, thus resulting in fast convergence to the new steady state. The economy thus escapes the recession. These results support the sceptics' arguments. I.e. that indeed, the benefits of supply-side reforms accrue in the long run and that such kind of reforms may not be an effective instrument for short-run fiscal stimulus.

This paper is related and partly motivated by a large research program that was initiated by Brock and Turnovsky (1981), Chamley (1981) and Summers (1981), who show that an elimination of capital income taxes would have very substantial positive economic effects. Working on variations of the same non-stochastic framework, Judd (1985a), (1985b) and (1987), Chamley (1986) and Lucas (1990) found that reducing capital taxes has significant welfare gains. Subsequently, this result was found to be robust in possibly stochastic environments (Zhu (1992), Jones, Manuelli and Rossi (1993), and Chari, Christiano and Kehoe (1994)). According to this literature, the optimal fiscal policy dictates a large capital tax rate in early periods and a decrease of the tax rate once the government has sufficiently high savings. However, this kind of policy is problematic in terms of implementability, since it is highly time-inconsistent. Because of this issue, several authors have turned to studies with constant tax rates. Finally, although a lot of the work in this area of research focuses on long-run optimal fiscal policies, some authors have explicitly addressed the transition after lowering capital income taxes or substituting with other forms of less distortionary taxation (Lucas (1990), Cooley and Hansen (1992), Chari et al. (1994), Garcia-Milà, Marcet and Ventura (1995) and Mendoza and Tesar (1998)). In these studies, when calculating welfare gains from low taxes on capital, the authors incorporate the transition period.

\section{Description of the Model}

The economy to be studied is described by a simple neoclassical growth model with uncertainty. It consists of a continuum of identical infinitely lived households, an infinitely lived firm and a government that finances its expenditures by levying taxes on capital and labour income. The source of uncertainty in the economy is an exogenous stochastic shock $Z_{t}$ to the technology. The households are endowed with some capital, and receive income from renting out their capital and supplying labour. Income is used to finance consumption and invest in additional capital. Income from capital and labour is taxed at constant rates $\tau$ and $\xi$ respectively. The households maximise expected discounted lifetime utility

$$
E_{0} \sum_{t=0}^{\infty} \beta^{t}\left(\log C_{t}+A L_{t}\right)
$$


over consumption $C_{t}$, leisure $L_{t}$, capital $K_{t}$ and investment $I_{t}$, subject to the budget constraint

$$
C_{t}+K_{t}-K_{t-1}=(1-\tau)\left(R_{t}-\delta\right) K_{t-1}+(1-\xi) W_{t} N_{t}
$$

where $N_{t} \equiv 1-L_{t}$ denotes hours worked and the evolution of capital is determined by $K_{t}=(1-\delta) K_{t-1}+I_{t}$, where $R_{t}, W_{t}$ denote the price of capital rental and the wage rate respectively. The parameters $\beta$ and $\delta$ denote the discount factor and the depreciation rate of capital respectively. Taxes on capital are after depreciation allowances. The representative firm produces output $Y_{t}$, rents capital, hires efficiency units of labour at a rate $W_{t}$, and maximises profits $Y_{t}-W_{t} N_{t}-R_{t} K_{t-1}$ in every period, subject to a Cobb-Douglas production function $Y_{t}=Z_{t} K_{t-1}^{\alpha} N_{t}^{1-\alpha}, 0<\alpha<1$, and to a technological shock, which evolves according to $\log Z_{t}=\rho \log Z_{t-1}+\varepsilon_{t}, \varepsilon_{t} \sim N\left(0, \sigma_{\varepsilon}^{2}\right)$ and $0<\rho<1$. Finally, the government has expenditures $G_{t}$ that are financed by levying taxes on capital and labour income, and maintains a balanced budget ${ }^{6}$

$$
G_{t}=\tau\left(R_{t}-\delta\right) K_{t-1}+\xi W_{t} N_{t}
$$

The competitive (RE) equilibrium for the economy is defined as a sequence of prices and allocations, a government policy $\{\tau, \xi\}$ and a sequence of government expenditures such that when households maximise utility and firms maximise profits taking prices and government policy as given, the chosen allocations are such that capital, labour and goods markets clear, and the government budget constraint is satisfied. The equilibrium can be summarised by the following set of equations:

$$
\begin{aligned}
1 & =\beta E_{t}\left[\left(\frac{C_{t+1}}{C_{t}}\right)^{-1}\left[(1-\tau)\left(R_{t+1}-\delta\right)+1\right]\right] \\
A C_{t} & =(1-\xi) W_{t} \\
K_{t-1} R_{t} & =\alpha Y_{t} \\
W_{t} N_{t} & =(1-\alpha) Y_{t} \\
C_{t}+K_{t} & =Y_{t}+(1-\delta) K_{t-1}-G_{t} \\
G_{t} & =\tau\left(R_{t}-\delta\right) K_{t-1}+\xi W_{t} N_{t} \\
Y_{t} & =Z_{t} K_{t-1}^{\alpha} N_{t}^{1-\alpha} \\
\log Z_{t} & =\rho \log Z_{t-1}+\varepsilon_{t}, \varepsilon_{t} \sim N\left(0, \sigma_{\varepsilon}^{2}\right)
\end{aligned}
$$

Since the aim of the paper is to quantify the differences of the transitions of a capital tax reform under RE and adaptive learning, this standard model facilitates comparisons and it also conforms with some of the related literature on supply-side economics (e.g. Chamley (1986) and Cooley and Hansen (1992)).

\footnotetext{
${ }^{6}$ Schmitt-Grohé and Uribe (1997) show that certain balanced-budget rules may lead to indeterminacies in a model very similar to the present one. Their findings suggest that endogenous labour tax rates are important for the existence of stationary sunspot equilibria. Therefore I model the fiscal policy so that such indeterminacies are not present, i.e. with fixed income tax rates and endogenous government expenditures. However, letting $\widetilde{G}_{t}+T R_{t}=G_{t}$, where $\left\{\widetilde{G}_{t}\right\}$ is an exogenous sequence of government expenditures and $\left\{T R_{t}\right\}$ is a sequence of endogenous lump-sum transfers, (3) is consistent with a balanced budget of the form $\widetilde{G}_{t}=\tau\left(R_{t}-\delta\right) K_{t-1}+\xi W_{t} N_{t}-T R_{t}$.
} 


\section{Rational Expectations and Adaptive Learning}

To solve the model I use the method of log-linearising around the steady state. ${ }^{7}$ Let $\bar{P}$ denote the steady state value of variable $P_{t}$ and let $p_{t} \equiv \log P_{t}-\log \bar{P}$. The set of $\log$-linearised equations that determines an REE is

$$
\begin{aligned}
0 & =E_{t}\left[c_{t}-c_{t+1}+(1-\beta+\beta \delta(1-\tau)) r_{t+1}\right] \\
0 & =w_{t}-c_{t} \\
c_{t} & =\frac{\bar{Y}}{\bar{C}} y_{t}-\frac{\bar{G}}{\bar{C}} g_{t}+\frac{(1-\delta) \bar{K}}{\bar{C}} k_{t-1}-\frac{\bar{K}}{\bar{C}} k_{t} \\
r_{t} & =z_{t}-(1-\alpha) k_{t-1}+(1-\alpha) n_{t} \\
y_{t} & =z_{t}+\alpha k_{t-1}+(1-\alpha) n_{t} \\
w_{t} & =z_{t}+\alpha k_{t-1}-\alpha n_{t} \\
g_{t} & =\frac{\tau \bar{R} \bar{K}}{\bar{G}}\left(r_{t}+k_{t-1}\right)-\frac{\tau \delta \bar{K}}{\bar{G}} k_{t-1}+\frac{\xi \bar{W} \bar{L}}{\bar{G}}\left(w_{t}+n_{t}\right)
\end{aligned}
$$

By eliminating all variables apart from $k$ and $z$ in the first (expectational) equation, one can write the model in the reduced form

$$
\begin{aligned}
k_{t} & =a_{1} E_{t} k_{t+1}+a_{2} k_{t-1}+b z_{t} \\
z_{t} & =\rho z_{t-1}+\varepsilon_{t}
\end{aligned}
$$

where the coefficients $a_{1}, a_{2}$ and $b$ depend on the parameters of the model. ${ }^{8}$ Let $x_{t}=\left(k_{t}, z_{t}\right)^{\prime}$. The REE of (19) is a minimal state variable (or fundamental) solution $k_{t}=\bar{\Phi}^{\prime} x_{t-1}+\theta \varepsilon_{t} \equiv$ $\bar{\phi}_{1} k_{t-1}+\bar{\phi}_{2} z_{t-1}+\theta \varepsilon_{t}$. Inserting this into (19), yields two solutions $\bar{\Phi}_{+}$and $\bar{\Phi}_{-}$:

$$
\bar{\Phi}_{+,-}=\left(\bar{\phi}_{1}, \bar{\phi}_{2}\right)^{\prime}=\left(\frac{1}{2 a_{1}}\left(1 \pm \sqrt{1-4 a_{1} a_{2}}\right), \frac{\rho b}{1-a_{1}\left(\rho+\bar{\phi}_{1}\right)}\right)^{\prime}
$$

It can be shown that when $\left|a_{1}+a_{2}\right|<1$, the only stationary solution is $\bar{\Phi}_{-}$. For $a_{1}$ and $a_{2}$ such that $\left|a_{1}+a_{2}\right|>1$ and $\left|a_{1} a_{2}\right|<1 / 4$, both solutions are stationary. For the remaining combinations of $a_{1}$ and $a_{2}$, both solutions are either non-stationary or non-real. I restrict attention to the stationary solutions.

I now relax the assumption of $\mathrm{RE}$ and assume that the households form expectations according to

$$
E_{t}^{*} k_{t+1}=\phi_{1 t} k_{t}+\phi_{2 t} z_{t}
$$

and estimate the vector of coefficients $\Phi_{t}$ in every period by using the available data and the observed forecasting error. The difference between (22) and rational expectations formation is that in (22) the conditional expectations do not coincide with the mathematical

\footnotetext{
${ }^{7}$ This also facilitates the analysis under adaptive learning. Although there have been some contributions for directly analysing non-linear models with adaptive learning (see Evans and Honkapohja (2001)), the literature still lacks a general treatment of non-linear learning dynamics. This is because the bulk of the results developed for economics based on stochastic approximation theory require that the evolution of the state variable is conditionally linear, which is not the case for the state variables in real business cycle models.

${ }^{8}$ Explicit expressions for the steady state and the coefficients are provided in Appendix A. The calculation of the coefficients in the reduced form of the log-linearised model were done using Mathematica 3.0.
} 
expectations implied by the probability distributions governing the structure of the economy. Rational agents are assumed to know the structure and the parameters of the model. Therefore their expectations are 'correct', in the sense that, if at time $t$ agents expect capital at $t+1$ to be $E_{t} k_{t+1}=\bar{\phi}_{1} k_{t}+\bar{\phi}_{2} z_{t}$, their expectation will be confirmed on average. In the same sense, learners do not form 'correct' expectations since, in general, they have less information than the rational agents. Implicit in the expectations formation (22) is that the learners are aware of how the evolution of the state variable relates to the evolution of the rest of the variables, but they are not aware of the true law of motion of the state variable. In a nutshell, the rational agents foresee while the learners forecast. ${ }^{9}$

Substituting the perceived law of motion (22) into the reduced form (19) implies an actual law of motion of capital

$$
k_{t}=T\left(\Phi_{t-1}\right)^{\prime} x_{t-1}+V\left(\Phi_{t-1}\right) \varepsilon_{t}
$$

where $T(\Phi) \equiv\left(T_{1}(\Phi), T_{2}(\Phi)\right)^{\prime}=\left(\left(1-a_{1} \phi_{1}\right)^{-1} a_{2},\left(1-a_{1} \phi_{1}\right)^{-1}\left(\rho a_{1} \phi_{2}+b \rho\right)\right)^{\prime}$ and $V(\Phi)=$ $\left(1-a_{1} \phi_{1}\right)^{-1}\left(a_{1} \phi_{2}+b\right)$. The agents are assumed to update $\Phi$ using the following recursive least squares algorithm

$$
\begin{aligned}
& \Phi_{t}=\Phi_{t-1}+\gamma_{t} S_{t-1}^{-1} x_{t-1}\left[x_{t-1}^{\prime}\left(T\left(\Phi_{t-1}\right)-\Phi_{t-1}\right)+V\left(\Phi_{t-1}\right) \varepsilon_{t}\right] \\
& S_{t}=S_{t-1}+\gamma_{t}\left(x_{t-1} x_{t-1}^{\prime}-S_{t-1}\right)
\end{aligned}
$$

where $x_{t-1}^{\prime}\left(T\left(\Phi_{t-1}\right)-\Phi_{t-1}\right)+V\left(\Phi_{t-1}\right) \varepsilon_{t}$ is the forecasting error in period $t, S_{t}$ is the second moment matrix estimate and the gain $\gamma_{t}$ is a deterministic positive decreasing sequence such that $\sum_{t=0}^{\infty} \gamma_{t}=\infty$ and $\sum_{t=0}^{\infty} \gamma_{t}^{2}<\infty$. Under this specification, it can be shown that an REE $\bar{\Phi}$ of the reduced form model (19) is stable under the recursive least squares learning algorithm (24), i.e. the algorithm converges locally and asymptotically to $\bar{\Phi}$ with some positive probability which is bounded from below by a sequence of numbers tending to one, if the following conditions are satisfied

$$
\frac{a_{1} a_{2}}{\left(1-a_{1} \bar{\phi}_{1}\right)^{2}}<1 \text { and } \frac{\rho a_{1}}{1-a_{1} \bar{\phi}_{1}}<1
$$

This result ensures that, if (25) hold and as more information becomes available, the learners will eventually learn how to form rational expectations, with a large probability. ${ }^{10}$ The reduced form model (19) is studied in Giannitsarou (2003a) and (2003b). It is shown that, for

\footnotetext{
${ }^{9}$ Other formulations for the expectations formation are possible as well. For example, Evans and Honkapohja (2001) consider a case where agents also learn about the relationship of capital with consumption. This introduces some technical complications for the analysis of real-time adaptive learning. For this reason, and since, strictly speaking, consumption is not a state variable it is not necessary to include it in the reduced form of the model. Moreover, one can consider scenarios where (22) includes a constant term, or agents also forecast the technological shock as well as the state variable. In both these cases learners have a smaller information set than the one assumed here. In this sense, the learners that form expectations according to (22) are the closest possible to the rational agents. The results presented in later sections, based on (22), do not differ qualitatively from the ones under these two alternative formulations. For the former and for all reasonable calibrations of the model, the results remain unchanged both asymptotically and in the short-run apart from the shift induced by the intercept. For the latter specification, the effects discussed later are slightly magnified in the very early periods of the model, but it can easily be verified that learning about the parameters of the technology shock can be achieved very fast and therefore the results are not significantly altered.

${ }^{10}$ This result derives as a direct application of the results of Marcet and Sargent (1989) and Evans and Honkapohja (1998).
} 
certain parameter regions, the stability of the REEs under learning is sensitive to the specification of the learning algorithm and the assumption of heterogeneous learning. However, if the parameters of the model are such that $\left|a_{1}+a_{2}\right|<1$, the unique stationary solution $\bar{\Phi}_{-}$is always learnable under least squares learning, stochastic gradient learning and under heterogeneous learning.

The reform to be analysed is one in which the government implements a permanent unanticipated reduction of the tax rate on capital at time $t=0$ from $\tau^{\text {old }}$ to $\tau^{\text {new }}{ }^{11}$ To study the tax reform under adaptive learning, I assume that before the reform, the economy has already converged to the (old) equilibrium. A gain sequence of the form $\gamma_{t}=1 /(t+N)$ is used in the least squares algorithm, where $N=40$, corresponding to ten years. ${ }^{12}$ The initial value for the technological shock is set to $z_{-1}=0$. The numerical simulation of the RE transition path consists of the following steps: (a) calculate the old and new steady states, (b) log-linearise around the new steady state and finding the coefficient $\bar{\Phi}^{\text {new }}$, (c) set the initial condition for capital, (d) simulate the transition of $k_{t}$ and (e) use the generated series for capital to simulate the rest of the variables. The process for simulating the path for learning is characterised by a crucial difference. Apart from the initial condition for capital, which is the same as for the RE case, the agents must now have an initial perception about $\Phi$. Since I have assumed that before the reform the agents have learned the pre-reform equilibrium, a natural choice is $\Phi_{-1}=\bar{\Phi}^{\text {old }}$ and $R_{-1}=\bar{M}^{\text {old }}$ where $\bar{M}^{\text {old }}=\lim _{t \rightarrow \infty} E\left[x_{t}\left(\bar{\Phi}^{\text {old }}\right) x_{t}\left(\bar{\Phi}^{\text {old }}\right)^{\prime}\right]$.

The set of parameters to be specified is $\left\{\alpha, \delta, \beta, \rho, \sigma_{\varepsilon}, \xi, \tau\right\}$. Since the emphasis is put on the properties of the REEs for different values of the fiscal parameters $\tau$ and $\xi$, I fix $A=2.54$, $\alpha=0.36, \delta=0.025, \beta=0.99, \rho=0.95$ and $\sigma_{\varepsilon}=0.00712$, and let $\tau$ and $\xi$ vary in the range $[0,1)$. The parameter $A$ is set such that in steady state, the households spend one third of their time working. The values for $\alpha, \delta, \beta, \rho$, and $\sigma_{\varepsilon}$ are chosen such that they conform with the majority of the real business cycle literature. For the above parameterisation and for all $\tau, \xi \in[0,1)$ it can easily be shown that $0<a_{1}+a_{2}<1$ (derivation omitted). Hence $\bar{\Phi}_{-}$is the unique stationary and learnable solution. Furthermore, I set $\tau^{o l d}=0.4$ and $\xi=0.25$. These values correspond to averages of the capital and labour tax rates estimates provided by Mendoza et al. (1994) for the US economy for the period $1965-1996 .{ }^{13}$ The implied

\footnotetext{
${ }^{11}$ The present analysis is in the spirit of Lucas (1990), Cooley and Hansen (1992) and Mendoza and Tesar (1998), and is limited to changes in time-invariant tax rates, thus the tax cut is assumed to be unanticipated. Some of Cooley and Hansen's results indicate that under RE, little changes if the tax rates are taken to be time-varying. Nevertheless, it is an open question how changing this assumption would affect the analysis with learning. On one hand, one could argue that since learners do not have any information/data about the new regime until a reform is undertaken, it should make no difference whether the reform is anticipated or not. On the other hand, if they anticipate tax cuts, it could be argued that they adjust their forecasting rules so as to treat the tax rates as time-varying parameters; in this case the technical analysis of learning would differ from the present one.

${ }^{12}$ Technically, this kind of gain sequence reduces the large variability of the estimates in the early periods, that results from OLS regressions with very few data points, and therefore reduces the probability of the estimates leaving the domain of attraction of $\bar{\Phi}$. Another way to increase the probability of convergence to the REE is to augment the learning algorithm with a projection facility, which prevents the estimates $\Phi_{t}$ from leaving the interior of a subset of the domain of attraction of $\bar{\Phi}$. A learning algorithm with a projection facility ensures almost sure local asymptotic convergence to the REE (see Marcet and Sargent (1989)). However, the projection facility has occasionally been criticised (e.g. Grandmont (1998)), and has thus been avoided in the present analysis.

${ }^{13}$ Other authors have used similar estimates. Lucas (1990) uses $\xi=0.4$ and $\tau=0.36$, Cooley and Hansen
} 
long-term output ratios for the pre-reform economy are $\bar{K} / \bar{Y}=8.61$ (implying annual ratio 2.15), $\bar{I} / \bar{Y}=0.21$ and $\bar{G} / \bar{Y}=0.21$. These ratios are within a reasonable range of reported ratios for US data, apart from the investment-output ratio which is slightly higher than the usual estimates. ${ }^{14}$ The transition to be analysed is after a complete elimination of capital taxation, hence $\tau^{\text {new }}=0$. The deterministic steady states of the variables before and after the reform are shown in table 1 . The numbers confirm the standard predictions of supply-side economics. The long run effects of eliminating capital income taxation are large: when the capital tax rate is set to zero, capital stock and investment are about $28 \%$ higher, consumption is about $10 \%$ higher and hours worked are about $2 \%$ lower. Finally, the preand post-reform RE solutions are $\bar{\Phi}^{\text {old }}=(0.9577,0.1220)^{\prime}$ and $\bar{\Phi}^{\text {new }}=(0.9418,0.1389)^{\prime}$.

\section{Transition Dynamics of a Capital Tax Reform}

Standard impulse response analysis consists of tracing the effect of a $1 \%$ change in the variable/parameter of interest on the rest of the variables. This effect is isolated by assuming that the variables are at steady state levels prior to the change. The choice of a $1 \%$ change is a normalisation that facilitates comparison between the effects of such changes in different models. This type of analysis is sufficient under RE, since the impulse response functions (IRFs) depend linearly on the state and the exogenous variables, and thus represent shifts and/or symmetric reflections of the standardised response to a $1 \%$ positive change. However, this is not true when agents learn adaptively. Consider for example a generic setup where the endogenous variable $p$ evolves according to $p_{t}=\gamma_{1, t-1} s_{t}+\gamma_{2, t-1} v_{t}$, where $s$ and $v$ are the state variable and an exogenous variable respectively. There are two possible effects that one might wish to identify, namely the effect of a shock to the exogenous variable $v$ and the effect of a structural shift in the economy. Assuming that the shock occurs at $t=0$, when agents are rational, they instantaneously recognise the 'correct' coefficients $\gamma_{1 t}$ and $\gamma_{2 t}$ and therefore the coefficients are constant for all $t$. But when agents learn, $\gamma_{1 t}$ and $\gamma_{2 t}$ are in general non-linear functions of time, the initial values of the state and exogenous variables, and the initial perceptions $\gamma_{1,0}$ and $\gamma_{2,0}$. Thus, a standard impulse response analysis cannot trace asymmetries that arise due to these non-linearities. A full impulse response analysis would include tracing the effects of all possible combinations of shocks and variables that determine the evolution of the coefficients $\gamma_{1 t}$ and $\gamma_{2 t}$, i.e. shocks to the exogenous variable, the parameters and the initial perceptions of the agents about the state variable and $\gamma_{1 t}$ and $\gamma_{2 t}$. Here, I restrict attention to the effects of the supply-side reform when this coincides with (a) a shock to the technology and (b) various levels of the pre-reform capital stock. An emphasis is put on scenarios where the tax reform coincides with negative exogenous shocks and/or a low pre-reform capital stock, as it is typical for fiscal policy makers to introduce

(1992) use $\tau=0.5$ and $\xi=0.23$, and Mendoza and Tesar (1998) use $\xi=0.291$ and $\tau=0.415$ (based on 1991 estimates from Mendoza et al., (1994)).

\footnotetext{
${ }^{14}$ For US data, Lucas (1990) reports $K / Y=2.4$ (annual) and $G / Y=0.21$; Maddison (1992) reports $K / Y \in[2.12,2.43]$ (depending on the period considered); Mendoza and Tesar (1998) report $I / Y=0.17$ and $G / Y=0.19$; Ventura (1999) reports annual $K / Y=2.89$; Ahmed and Rogers (2000) report $I / Y \in[0.14,0.23]$ and $G / Y \in[0.12,0.22]$ (depending on the period considered). Furthermore, based on quarterly data for the period $1959-2001$, I have calculated $I / Y=0.18$ and $G / Y=0.19$ (source OECD, Quarterly National Accounts).
} 
reforms when a recessionary phase of the economy is imminent. ${ }^{15}$

As a benchmark, I summarise the impulse response analysis with RE. IRFs isolating solely the effect of the change in the capital tax rate are consistent with the findings of existing literature (e.g. Cooley and Hansen (1992) and Mendoza and Tesar (1998), for the closed economy case). I find that on impact, as capital starts accumulating towards the new steady state, the agents have incentives to consume less and work more (in order to invest and accumulate more capital). Hence labour initially overshoots while consumption undershoots. Then, labour gradually settles at a lower steady state, while consumption settles at a higher steady state.

4.1. The Effect of the Shock to Technology. Figure 1 presents IRFs for capital and output for three different values of the shock to technology. The vertical and the horizontal axes represent percentage deviations from the post-reform steady state values of the variables and years after the reform respectively. The solid lines correspond to the responses of the economy of learners and the dashed ones to the responses of the economy of rational agents. The dotted horizontal lines correspond to the pre-reform steady states of the variables. The middle plots depict responses solely due to the change in $\tau\left(\varepsilon_{0}=0\right.$ and $\left.K_{-1}=\bar{K}^{\text {old }}\right)$. The left hand side plots are the responses coinciding with a negative shock, $\varepsilon_{0}=-0.03$, and the right hand side plots show the responses coinciding with a positive shock, $\varepsilon_{0}=0.03$. Given the standard deviation $\sigma_{\varepsilon}=0.00712$, shocks in the range [ $\left.-0.03,0.03\right]$ cover $99 \%$ of the probability mass and the IRFs within this range vary smoothly as functions of the shock.

The sensitivity of the variables to the technological shock becomes clear from these plots. When the shock is negative, the IRFs with learning differ significantly from the responses with RE. As the shock becomes larger these differences are smoothed out, indicating that the impulse responses with learning exhibit asymmetries with respect to shocks to the technology. To see why these asymmetries are present, consider the first period after the reform $(t=1)$. The learners' forecast about the evolution of capital is solely based on past perceptions about the coefficients and does not incorporate the change in $\tau$, whereas the rational agents instantaneously calculate $\bar{\Phi}^{n e w}$. Using (23), the impulse response for capital with learning is $k_{1}=T_{1}\left(\phi_{1,0}\right) k_{0}+V\left(\Phi_{0}\right) \varepsilon_{0}$. Given the parameterisation, the function $T_{1}(\cdot)$ that maps the perceived to the actual elasticity of capital is increasing. This implies that the higher $\phi_{1}$ is perceived to be, the slower capital adjusts towards the new steady state. Therefore, since $\bar{\phi}_{1}^{\text {old }}>\bar{\phi}_{1}^{\text {new }}$, and given that $k_{-1}^{A L}=k_{-1}^{R E}$, in period $t=0$ capital will adjust to a higher level with $\mathrm{RE}$ than with learning. A period later, at $t=1$, the actual realisation of capital with learning is determined by the estimate $\Phi_{0}$, formed at $t=0$ using

$$
\Phi_{0}=\Phi_{-1}+\frac{1}{N} S_{-1}^{-1} x_{-1}\left[x_{-1}^{\prime}\left(T\left(\Phi_{-1}\right)-\Phi_{-1}\right)+V\left(\Phi_{-1}\right) \varepsilon_{0}\right]
$$

Hence, the actual realisation $k_{1}$ depends on how the estimates $\Phi$ adjust. Consider the first row of

$$
\left(\begin{array}{c}
k_{-1}^{2}\left(T_{1}\left(\bar{\Phi}^{\text {old }}\right)-\bar{\phi}_{1}^{\text {old }}\right)+k_{-1} z_{-1}\left(T_{2}\left(\bar{\Phi}^{\text {old }}\right)-\bar{\phi}_{2}^{\text {old }}\right)+k_{-1} V\left(\bar{\Phi}^{\text {old }}\right) \varepsilon_{0} \\
k_{-1} z_{-1}\left(T_{1}\left(\bar{\Phi}^{\text {old }}\right)-\bar{\phi}_{1}^{\text {old }}\right)+z_{-1}^{2}\left(T_{2}\left(\bar{\Phi}^{\text {old }}\right)-\bar{\phi}_{2}^{\text {old }}\right)+z_{-1} V\left(\bar{\Phi}^{\text {old }}\right) \varepsilon_{0}
\end{array}\right)
$$

\footnotetext{
${ }^{15}$ The computational analysis in the sections that follow was done using a set of codes in Matlab 5.3. The full toolbox is available upon request. For various early calculations, Uhlig's (1999) toolkit was employed. The author acknowledges Harald Uhlig for making his programs available.
} 
The estimate $\Phi_{0}$ linearly on $\varepsilon_{0}$. It can be shown that there exists a value $\widetilde{\varepsilon}$ such that if $\varepsilon_{0}<\widetilde{\varepsilon}<0$, the estimate $\phi_{1,0}$ adjusts upwards, in the opposite direction of where it should adjust to. Moreover, there exists a value $\widehat{\varepsilon}$ such that if $0<\widehat{\varepsilon}<\varepsilon_{0}$, the estimate $\phi_{1,0}$ adjusts downwards, to a level below the REE $\bar{\phi}_{1}$. For all plausible values of initial capital stock, $\widetilde{\varepsilon}$ is very near zero and $\widehat{\varepsilon}$ is approximately 0.023 (large relative to the standard deviation $\left.\sigma_{\varepsilon}=0.00712\right)$. In other words, any shock $\varepsilon_{0}<0.023$ implies a slow-down of the adjustment of capital, as compared to the response of capital under RE. The smaller the shock is, the slower capital adjusts, and in particular, when the shock is negative, the rate of adjustment is even slower than under the pre-reform regime. This means that a bad shock coinciding with the tax cut sends out a 'false alarm' to the agents, making them believe that under the new regime, capital is more inelastic than under the old regime, and therefore it accumulates very slowly. Since the actual evolution of capital depends on agents' expectations about it, this effect remains for some time until the forecasting error becomes smaller and the agents start forming RE. In contrast, a positive shock enables the agents to adjust their expectations towards the REE faster, as it sends the least squares estimate of $\Phi$ in the right direction. In extreme cases of large positive shocks, not only do the agents realise that the economy is moving towards a higher steady state, but the extreme optimism results in capital accumulating even faster than under RE.

These effects are transmitted in a natural manner to the rest of the variables. Although qualitatively similar to the corresponding responses under RE, the slower accumulation of capital results in somewhat smoother reactions of the variables to the change of the capital tax rate. The slow capital accumulation for the learners gives them less incentive to invest. Therefore the early drop in consumption and increase in labour are smaller than with RE. In effect, lower labour supply combined with slow capital accumulation and bad productivity shocks, results in a recessionary episode in production that lasts approximately 3.5 years before output starts to rise above the pre-reform steady state. ${ }^{16}$ When a large positive shock is realised, production in the economy of learners overshoots in the early periods to a level that is marginally higher than the one under rational expectations.

4.2. The Effect of the Initial Capital Stock. Further asymmetries in the IRFs with learning arise as a result of varying the level of the pre-reform capital stock. With arguments similar to those in section 4.1, it can be shown that if $\varepsilon_{0}<0$, the deviation of the estimates from the equilibrium $\bar{\Phi}^{\text {new }}$ is decreasing in both the shock $\varepsilon_{0}$ and the initial (pre-reform) capital stock $k_{-1}$. I.e. the smaller the shock is or the lower the level of the capital stock, the further away the estimates $\Phi$ deviate from the equilibrium. Furthermore, this deviation has the property of increasing differences, i.e. if the reform coincides with a negative shock to the technology and the capital stock is at a low level, one effect reinforces the other in that the adjustment of capital is slower than if the two isolated effects were to be added together. Thus the pessimism in the agents' expectations about the evolution of capital when the economy is subjected to a negative shock is magnified if the economy is already in

\footnotetext{
${ }^{16}$ Note that the kinks in the impulse response functions of output with adaptive learning appear because in period $t=0$ output depends on post-reform parameters (coefficients $a_{1}, a_{2}$ and $b$ of the reduced form) and on the pre-reform beliefs $\Phi_{-1}$. It is only from period $t=1$ that the new fiscal regime is fully incorporated in the evolution of output (as well as the rest of the variables).
} 
a recessionary phase. This can be verified by the IRFs of capital and output in figure $2 .{ }^{17}$

4.3. Speeds of Convergence. It has already become clear that the variables of the two economies with adaptive learning and $\mathrm{RE}$ do not converge to the new steady state with the same speed. Specifically, figures 1 and 2 indicate that convergence takes longer with adaptive learning, when the impulse responses are plotted for negative shocks. To quantify this effect better, I provide numerical estimates of the speeds of convergence for shocks producing impulse responses in the range $\varepsilon_{0} \in[-0.03,0.03]$, when $K_{-1}$ is at the pre-reform steady state. I define the speed of convergence to the new steady state of the impulse response of a variable $p$ to a shock $\varepsilon_{0}$, as the time period $t^{*}\left(\varepsilon_{0}, p\right)$ such that

$$
t^{*}\left(\varepsilon_{0}, p\right)=\min \left\{t:\left\|\mathbf{p}^{t}\left(\varepsilon_{0}\right)\right\|=0\right\}
$$

where $\mathbf{p}^{t}\left(\varepsilon_{0}\right)$ is the vector $\left(p_{t}\left(\varepsilon_{0}\right), p_{t+1}\left(\varepsilon_{0}\right), p_{t+2}\left(\varepsilon_{0}\right), \ldots\right)$. I.e., the speed of convergence is the earliest period such that the variable does not deviate from the new steady state from that period and on. For the numerical estimation of the speeds of convergence, I use a stopping criterion with tolerance 0.0004 , corresponding approximately to $5 \%$ of the standard deviation of $\varepsilon_{t}$. The relevant speeds of convergence for capital and output are presented in figure 3 . In each plot the horizontal axis represents the size of the shock producing the impulse response and the vertical axis represents the period in years where convergence of the variable is achieved. The solid lines represent the speeds of the variables with adaptive learning and the dashed lines the speeds with RE.

It now becomes clear how negative shocks coinciding with the tax reform dramatically slow down the convergence of the variables to the new steady state when adaptive learning is employed. The difference between the speeds of convergence can be up to twenty years for a shock $\varepsilon_{0}=-0.03$. For large positive shocks however, responses with both methods converge with almost the same speed. Similar plots for the same range of shocks and initial value of capital $20 \%$ below the original steady state (not included here) reveal that the impulse responses under RE remain unaltered, while under adaptive learning, convergence is even slower for negative shocks, confirming the observations of section 4.2.

4.4. Sensitivity Analysis. To test the robustness of the results, I repeat the impulse response analysis for two variations of the model. First, I consider a model where the tax revenue from capital income is substituted by revenue from taxes on labour income, i.e. $\xi^{\text {new }}=0.3405$ is determined by requiring that $\bar{G}^{\text {new }} / \bar{Y}^{\text {new }}=\bar{G}^{\text {old }} / \bar{Y}^{\text {old }}$ (case (a)). Second I consider a model where the supply of labour is inelastic, i.e. $N_{t}=1$ for all $t$ (case (b)). I will refer to the original case as the benchmark case. Figure 4 shows the impulse responses of capital for the benchmark case and cases (a) and (b) for the scenarios $\left\{\varepsilon_{0}=0, K_{-1}=\bar{K}^{\text {old }}\right\}$, $\left\{\varepsilon_{0}=-0.03, K_{-1}=\bar{K}^{\text {old }}\right\}$ and $\left\{\varepsilon_{0}=0, K_{-1}=20 \%\right.$ below $\left.\bar{K}^{\text {old }}\right\} .{ }^{18}$ The corresponding REEs for the three cases are presented in table 2. In case (a) the labour income tax rate increases, thus the steady state level of labour supply will be lower than in the benchmark case. The same is true for production, capital, consumption and investment. As expected, the differences between the IRFs of the benchmark case and case (a) are not significant. In

\footnotetext{
${ }^{17}$ Figure 2 should be read in the same way as figure 1.

${ }^{18}$ The graphs should be read in the same way as in figures 1 and 2 .
} 
case (b), the post-reform increases in the steady state values of the variables are larger than in the benchmark case. Furthermore, $\bar{\phi}_{1}$ is large, resulting in a slower adjustment of capital under learning. This is because when labour is inelastic, the agents respond to a margin less than in the benchmark case. For this reason, the impulses with learning are also more sensitive to negative shocks and low initial capital, and the differences between the impulses for learning and RE are larger relative to the benchmark case. Nevertheless, although the effects are somewhat magnified, the results are qualitatively robust to this variation of the model. Finally, impulse response analysis for reforms where the capital income tax rate is reduced to some positive rate, instead of being eliminated, reveals that the effects described in sections 4.1 and 4.2 are qualitatively the same as in the benchmark case. Recall however that all the analyses are based on percentage deviations from the post-reform steady state, and therefore the magnitude of the effects on the levels of the variables is smaller when the tax cut is smaller.

\section{WELFARE}

In order to analyse the implications of the differences between learning and RE for welfare, I use a modified version of the standard welfare measure. The commonly used measure is the percentage amount by which consumption should change in all periods in the pre-reform economy so that agents are as well off as in the post reform economy (including the transition) leaving leisure unchanged. ${ }^{19}$ To capture possible asymmetries arising in the welfare gains with adaptive learning, I modify this definition by calculating welfare gains conditional on the initial random shock to technology. I.e., given an arbitrary initial shock $\varepsilon$, the conditional welfare gain is the percentage $\omega(\varepsilon)$ that satisfies

$$
\begin{aligned}
& E_{0}\left[\sum_{t=0}^{\infty} \beta^{t}\left[\log \left(C_{t}^{\text {old }}\left(1+\frac{\omega(\varepsilon)}{100}\right)\right)+A L_{t}^{\text {old }}\right] \mid \varepsilon_{0}=\varepsilon\right] \\
= & E_{0}\left[\sum_{t=0}^{\infty} \beta^{t}\left[\log \left(C_{t}^{\text {new }}\right)+A L_{t}^{\text {new }}\right] \mid \varepsilon_{0}=\varepsilon\right]
\end{aligned}
$$

Figure 5 displays the conditional welfare gains for adaptive learning and $\mathrm{RE}$ as functions of $\varepsilon_{0} \in[-0.03,0.03]$, based on simulations of length $T=2,000$ periods. It is evident from this plot that for the economy of learners, $\omega\left(\varepsilon_{0}\right)$ is a non-linear function. For all $\varepsilon_{0}<\widehat{\varepsilon}$ the gains of learners are smaller than the gains of rational agents, and this difference is increasingly larger, the smaller $\varepsilon_{0}$ is. For $\varepsilon_{0}=\widehat{\varepsilon}$ the gains are equal and for $\varepsilon_{0}>\widehat{\varepsilon}$ the gains with learning are marginally larger. The plotted welfare gains are consistent with the findings of the previous section: learners are in general less better off than rational agents, unless they observe very good 'news' when the reform is implemented. In particular, they are increasingly less better off than the rational agents, the worse the news is. It should be noted however, that these differences between the welfare gains of rational agents and learners are not very large. For the extreme realisation of $\varepsilon_{0}=-0.03$ the difference is approximately 0.45 percentage points.

\footnotetext{
${ }^{19}$ This measure has been used by Lucas (1990), Cooley and Hansen (1992), Chari et al. (1994) and GarciaMilà et al. (1995).
} 


\section{Discussion and Policy Implications}

It is evident from the impulse response analysis that there are two key factors that determine the transition of the variables after an elimination of capital income taxes: (a) the state of the economy and (b) the sign and size of the exogenous shocks at the time of the implementation of the reform. As an illustration, I simulate the evolution of the output levels with and without a supply-side reform for two realisations of the exogenous random shocks. For the first realisation, which I call recessionary shocks, the economy is subjected to consecutive negative shocks in the first two quarters after the reform takes place. For the second realisation, which I call expansionary shocks, the economy is subjected to consecutive positive shocks in the first two quarters after the reform. For the remaining quarters, the realisations of all random errors are the same. What emerges from this exercise reinforces the findings of the impulse response analysis. When the reform coincides with bad shocks to the economy (figure 6), the learners fail to interpret it as a change towards a higher steady state, and as a result the economy falls into a recession. On the other hand, despite the negative shocks, the economy of rational agents escapes the recession. If there had been no reform, output would evolve in the same way both under RE and under learning, since it has been assumed that learning has already converged to the REE. Although the magnitude of the recession is somewhat reduced for the economy of learners when the tax cuts are introduced, the evolution of output stays closer to the corresponding 'no-reform' series than to the RE series for at least the first three years. Furthermore, when the reform coincides with good shocks to the economy (figure 7) the learners' expectations 'become' rational very fast, and therefore the benefits of the reform are immediate. Interestingly, output in the economy of learners is marginally higher than output in the economy of rational agents for some time after the reform.

The results are driven by two factors, the adjustment inertia of the learners and the self-referential nature of the model. When agents learn, their expectations about future net returns on investment, and hence their decisions about consumption, are based on the information they currently have. Because in the early periods after the reform agents have no or very little information about the effects of the new regime, they interpret shocks to the economy as fluctuations around the pre-reform steady state (adjustment inertia). Moreover, since their expectations influence the true evolution of the economy, 'good' shocks boost the optimism of the agents so that they find the new and better steady state fast; 'bad' shocks on the other hand, keep the economy far away from the higher steady state for a long time, since the agents' pessimistic expectations, and therefore decisions, do not allow the economy to grow (self-referential nature of the model). In contrast, rational agents, who have perfect foresight (i.e. no adjustment inertia) realise immediately after the reform that the new tax rates imply higher future returns whatever shocks the economy is currently subjected to.

In practice, supply-side reforms, and in particular capital tax cuts, are designed to boost incentives to invest. Experience however suggests that occasionally such reforms take a long time to bring about the desired effects. The results presented here seem to agree with this observation. In particular, if such reforms are implemented as a measure for short-run fiscal stimulus of an economy heading towards recession, they are likely to be unsuccessful in achieving this goal. They also suggest that such reforms are considerably more effective when they are implemented during a boom. In a sense, appropriate tax cuts can play the 
role of an insurance policy against future recession. Nevertheless, I should stress that the results do not suggest that policy makers should refrain from introducing a tax cut during a recessionary phase: welfare-wise, the agents would still be better off than if the reform was not implemented (but not as much as they would be if the policy was implemented during an expansionary phase), but the effects that policy makers aim for would will not come about for a long period of time.

\section{CONCLUSiOn}

The present analysis re-examines the transition dynamics of a supply-side reform under the hypothesis of adaptive learning. I have found that, due to the adjustment inertia of the agents that learn and the self-referential nature of the model, the transition of the economy is sensitive to the exogenous shocks and the state of the economy at the time of the reform. The findings suggest that capital tax cuts may not be an appropriate instrument for shortrun fiscal stimulus of an economy heading towards recession, but it could yield significant short-run benefits if implemented when the economy is booming.

Based on this analysis, I conjecture that the qualitative wedge between transition dynamics under RE and learning is caused neither by the specifics of the model nor by the specific learning algorithm. It seems that the driving force is the inertia of adjustment that would be present in any economy of learners that undergoes a large structural change. Having isolated the differences between the transitions with learning and $\mathrm{RE}$ in the framework of a simple and standard model, it would be interesting to expand the analysis to richer versions the model, for example variations with agent heterogeneity. This would allow for an examination of redistributive effects along the lines of Garcia-Milà et al. (1995). Another direction for further research is to analyse a sequential reduction versus a one-off elimination of capital income taxation.

\section{A. Appendix}

Define

$$
\begin{aligned}
D= & {[1-\beta(1-\alpha)(1-\delta+\delta \tau)][\bar{Y}-\xi \bar{W} \bar{L}+\bar{K}(1-\delta+\delta \tau-\tau \bar{R})] } \\
& +\alpha \bar{K}(1-\delta+\delta \tau-\tau \bar{R})
\end{aligned}
$$

The coefficients of the reduced form (19) are

$$
\begin{aligned}
& a_{1}=\{[1-\beta(1-\alpha)(1-\delta(1-\tau))] \bar{K}\} / D \\
& a_{2}=\{\alpha[\bar{Y}-\xi \bar{W} \bar{L}+\bar{K}(1-\delta(1-\tau)-\tau \bar{R}]\} / D \\
& b_{1}=\{(1-\rho)(\bar{Y}-\xi \bar{W} \bar{L}-\tau \bar{K} \bar{R})+\beta(1-\tau) \rho \bar{R} \bar{C}\} / D
\end{aligned}
$$

The steady state is

$$
\begin{array}{lll}
\bar{K}=\frac{(1-\alpha)(1-\xi) \alpha\left(\frac{\bar{R}}{\alpha}\right)^{-\frac{\alpha}{1-\alpha}}}{A[\bar{R}-\alpha \delta-\xi \bar{R}+\alpha \xi \bar{R}-\alpha \tau \bar{R}+\alpha \delta \tau}, & \bar{R}=\frac{1-\beta+\delta \beta(1-\tau)}{\beta(1-\tau)}, & \bar{Y}=\frac{\bar{K} \bar{R}}{\alpha} \\
\bar{G}=\bar{K}\left[\tau(\bar{R}-\delta)+\frac{\xi(1-\alpha)}{\alpha} \bar{R}\right], & \bar{W}=(1-\alpha)\left(\frac{\bar{R}}{\alpha}\right)^{-\frac{\alpha}{1-\alpha}}, & \bar{I}=\delta \bar{K} \\
\bar{C}=\frac{1}{A}(1-\xi)(1-\alpha)\left(\frac{\bar{R}}{\alpha}\right)^{-\frac{\alpha}{1-\alpha}}, & \bar{L}=\left(\frac{\bar{R}}{\alpha}\right)^{\frac{1}{1-\alpha}} \bar{K}, & \bar{Z}=1
\end{array}
$$




\section{REFERENCES}

[1] Ahmed, S. and J. H. Rogers, 2000. "Inflation and the Great Ratios: Long Term Evidence from the U.S.", Journal of Monetary Economics, 45, 3 - 35.

[2] Brock, W. A. and S. J. Turnovski, 1981. "The Analysis of Macroeconomic Policies in Perfect Foresight Equilibrium," International Economic Review, 22, 179 - 209.

[3] Chamley, C. P., 1981. "The Welfare Cost of Capital Income Taxation in a Growing Economy," Journal of Political Economy, 89, 468 - 496.

[4] Chamley, C. P., 1986. "Optimal Taxation of Capital Income in General Equilibrium with Infinite Lives," Econometrica, 54, 607 - 622.

[5] Chari, V. V., L. J. Christiano, and P. J. Kehoe, 1994. "Optimal Fiscal Policy in a Business Cycle Model," Journal of Political Economy, 102, 617 - 52.

[6] Cooley, T. F. and G. D. Hansen, 1992. "Tax Distortions in a Neoclassical Monetary Economy," Journal of Economic Theory, 58, 290 - 316.

[7] Evans, G. and S. Honkapohja, 1998. "Convergence of Learning Algorithms without a Projection Facility", Journal of Mathematical Economics, 30, 59 - 86.

[8] Evans, G. and S. Honkapohja, 2001. "Learning and Expectations in Macroeconomics," Princeton University Press.

[9] Garcia-Milà, T., A. Marcet and E. Ventura, 1995. "Supply Side Interventions and Redistribution," Economics Working Papers Series, Universitat Pompeu Fabra.

[10] Giannitsarou, C., 2003a. "Heterogeneous Learning". Forthcoming in Review of Economic Dynamics.

[11] Giannitsarou, C., 2003b. "E-Stability Does Not Imply Learnability". Mimeograph.

[12] Grandmont, J.-M., 1998. "Expectations Formation and Stability of Large Socioeconomic Systems," Econometrica, 66, 741 - 781.

[13] Jones, L. E., R. E. Manuelli and P. E. Rossi, 1993. "Optimal Taxation in Models of Endogenous Growth," Journal of Political Economy, 101, 485 - 517.

[14] Judd, K., 1985a. "Short-Run Analysis of Fiscal Policy in a Simple Perfect Foresight Model," Journal of Political Economy, 93, 298 - 319.

[15] Judd, K., 1985b. "Redistributive Taxation in a Simple Perfect Foresight Model," Journal of Public Economics, 28, 59 - 83.

[16] Judd, K., 1987. "The Welfare Cost of Factor Taxation in a Perfect Foresight Model," Journal of Political Economy, 95, 675 - 709.

[17] Judd, K., 1990. "Supply-Side Economics: An Analytical Review," Oxford Economic Papers, 42, 3 - 42. 
[18] Maddison, A., 1995. "Monitoring the World Economy", OECD.

[19] Marcet, A. and T. Sargent, 1989. "Convergence of Least Squares Mechanisms in SelfReferential Linear Stochastic Models," Journal of Economic Theory, 48, 337 - 368.

[20] Mendoza, E. G., A. Razin and L. L. Tesar, 1994. "Effective Tax Rates in Macroeconomics: Cross-Country Estimates of Tax Rates on Factor Incomes and Consumption," Journal Monetary Economics, 34 (3), 297 - 323.

[21] Mendoza, E. G. and L. L. Tesar, 1998. "The International Ramifications of Tax Reforms: Supply-Side Economics in a Global Economy," American Economic Review, 88, 226 245 .

[22] Schmitt-Grohé, S. and M. Uribe, 1997. "Balanced-Budget Rules, Distortionary Taxes, and Aggregate Instability," Journal of Political Economy, 105, 976 - 1000.

[23] Summers, L. H., 1981. "Capital Taxation and Accumulation in a Life Cycle Growth Model," American Economic Review, 71, 533 - 544.

[24] Uhlig, H., 1999. "A Toolkit for Analysing Nonlinear Dynamic Stochastic Models Easily," in "Computational Methods for the Study of Dynamic Economies", ed. R. Marimon and A. Scott, Oxford University Press.

[25] Ventura, G., 1999. "Flat Tax Reform: A Quantitative Exploration", Journal of Economic Dynamics and Control, 23, 1425 - 1458.

[26] Zhu, X., 1992. "Optimal Fiscal Policy in a Stochastic Growth Model," Journal of Economic Theory, 58, 250 - 89. 


\begin{tabular}{lcccccccc} 
& $\bar{Y}$ & $\bar{K}$ & $\bar{C}$ & $\bar{I}$ & $\bar{R}$ & $\bar{W}$ & $\bar{N}$ & $\bar{R}^{\text {net }}$ \\
\hline old & 1.1186 & 9.6261 & 0.6341 & 0.2406 & 0.0418 & 2.1478 & 0.3333 & 0.01008 \\
new & 1.1994 & 12.3014 & 0.6999 & 0.3075 & 0.0351 & 2.3706 & 0.3238 & 0.01010 \\
\hline
\end{tabular}

Table 1: Steady States

\begin{tabular}{lccc} 
& Benchmark & Substitution & Inelastic labour \\
\hline Pre-reform REE & $(0.9576,0.1221)$ & $(0.9576,0.1221)$ & $(0.9743,0.0585)$ \\
Post-reform REE & $(0.9418,0.1388)$ & $(0.9418,0.1351)$ & $(0.9671,0.0640)$ \\
\hline
\end{tabular}

Table 2: Rational Expectations Equilibria 

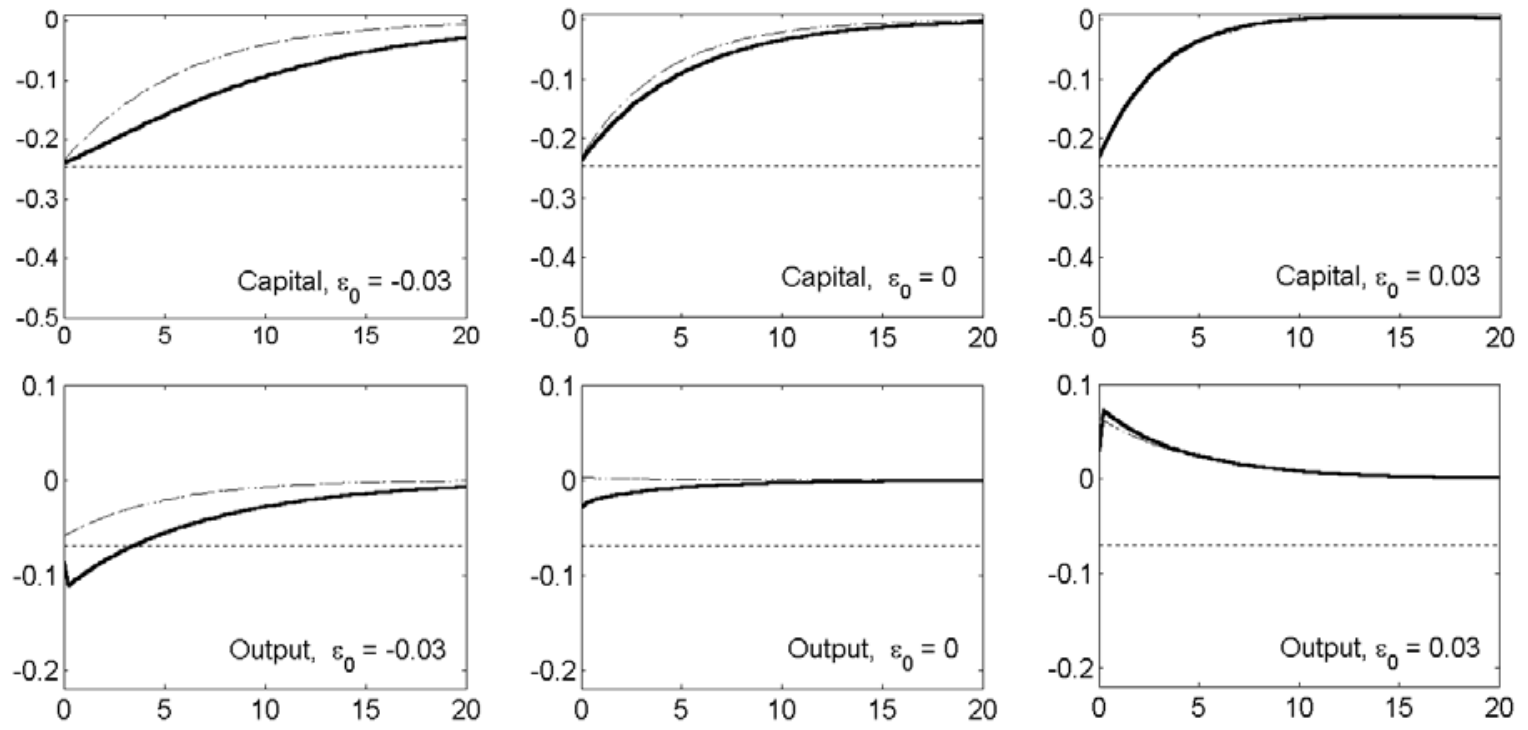

Figure 1:
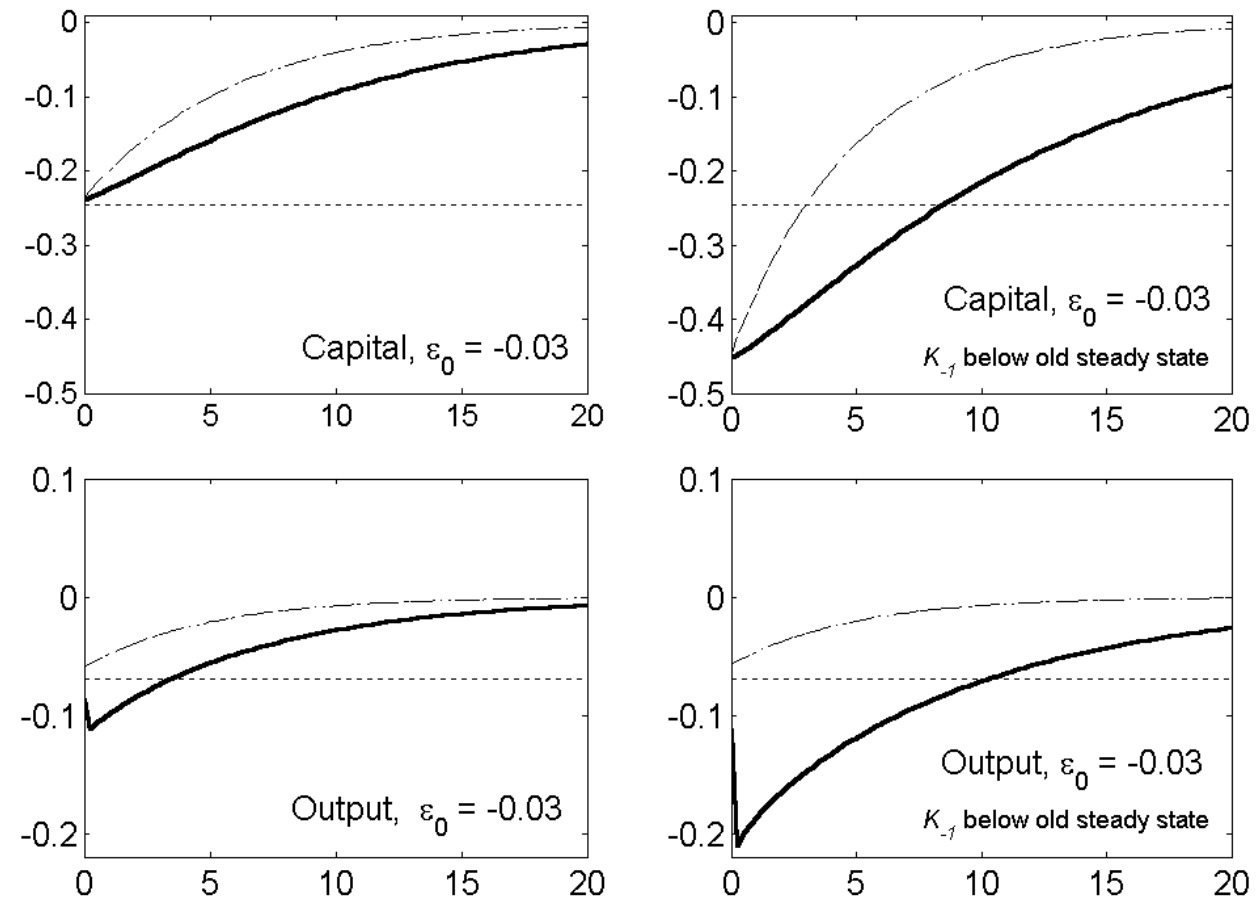

Figure 2: 

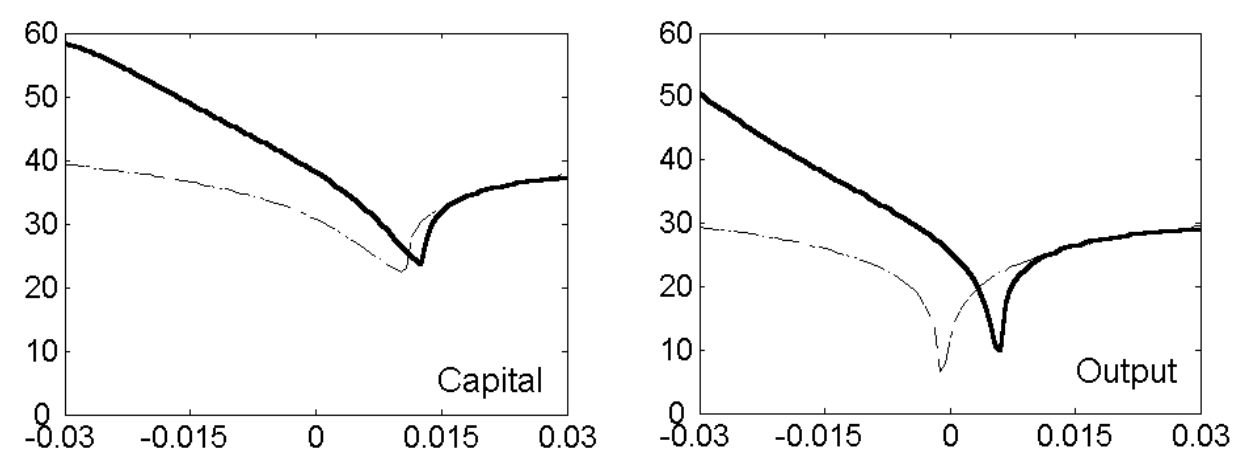

Figure 3:
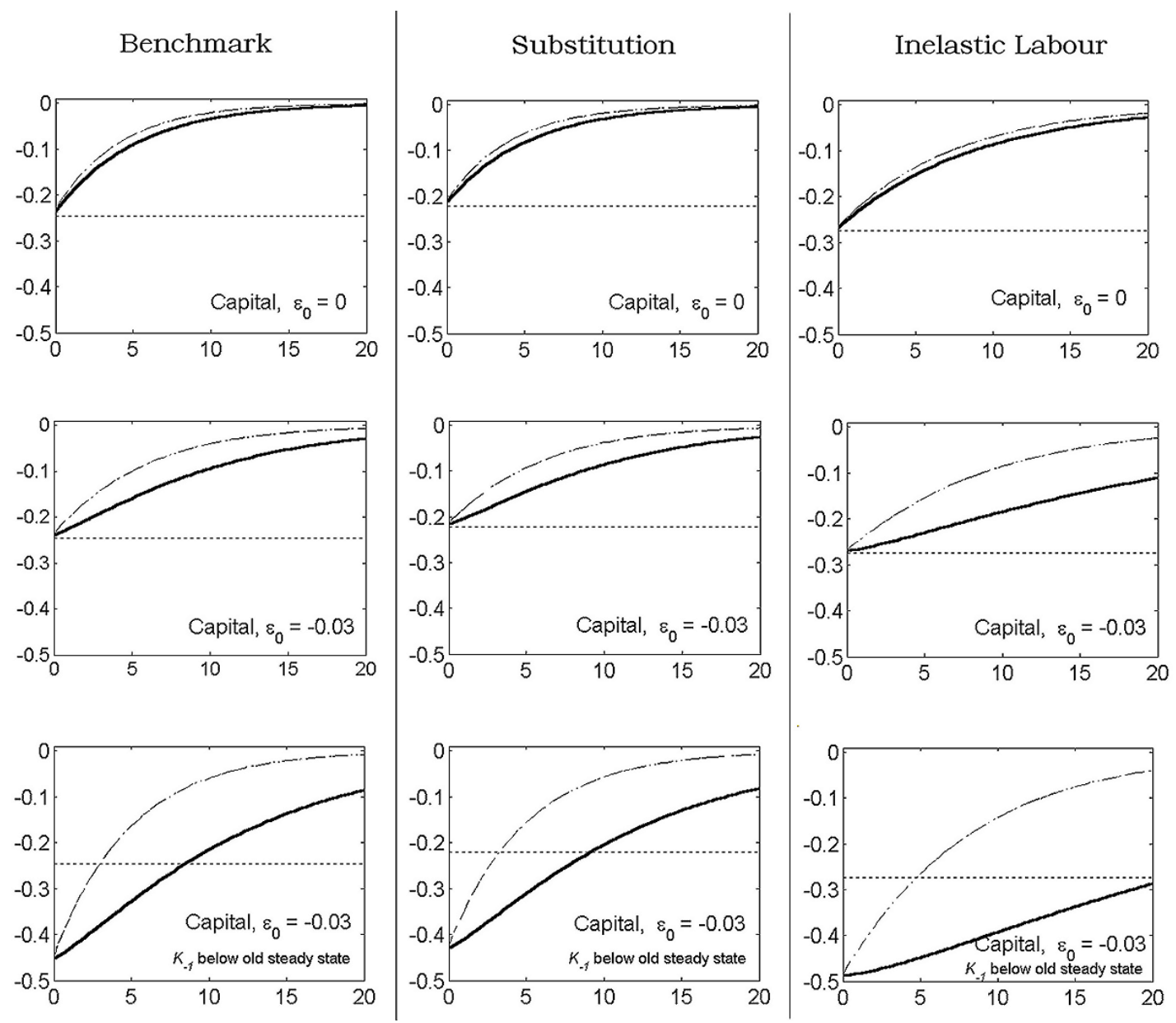

Figure 4: 


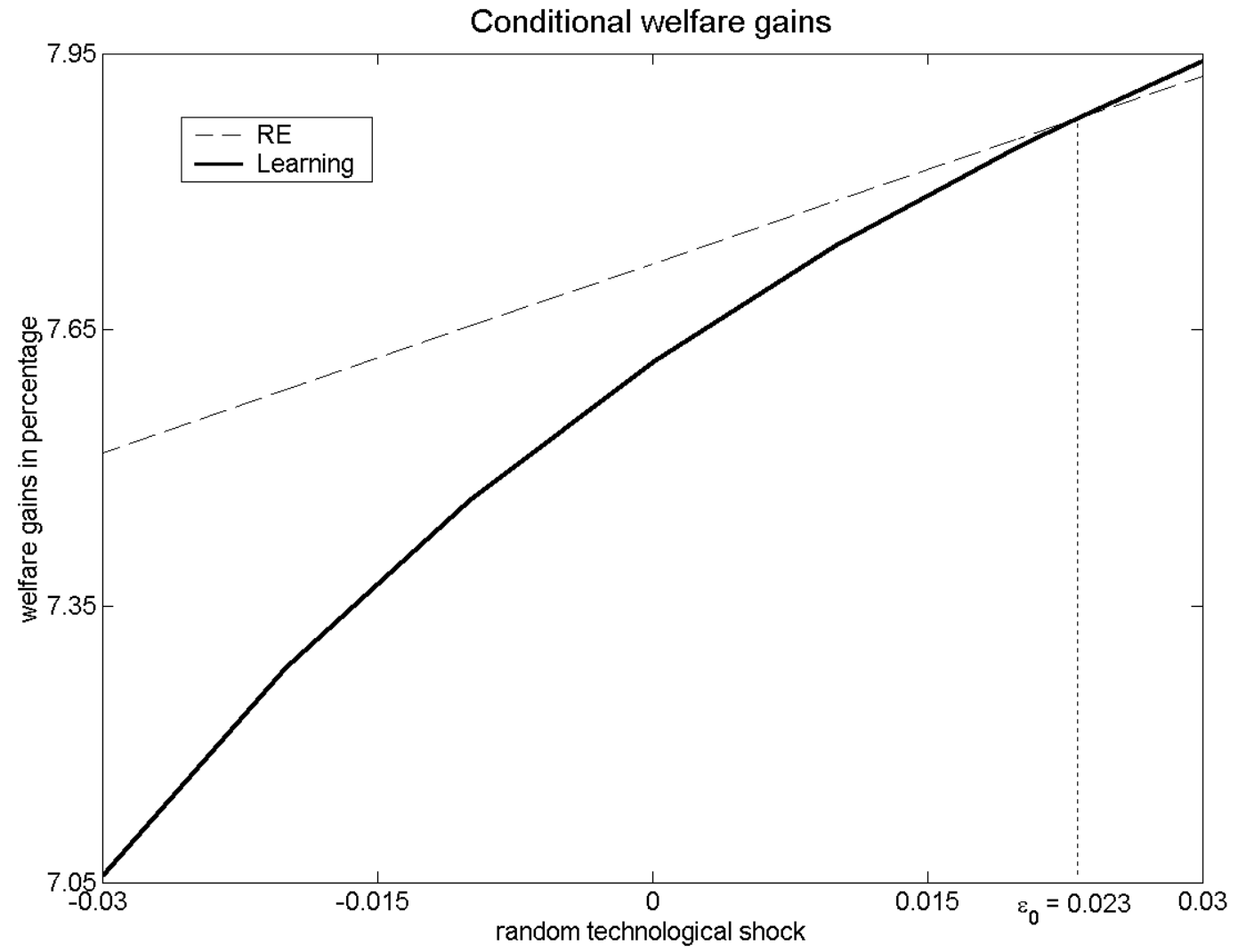

Figure 5: 


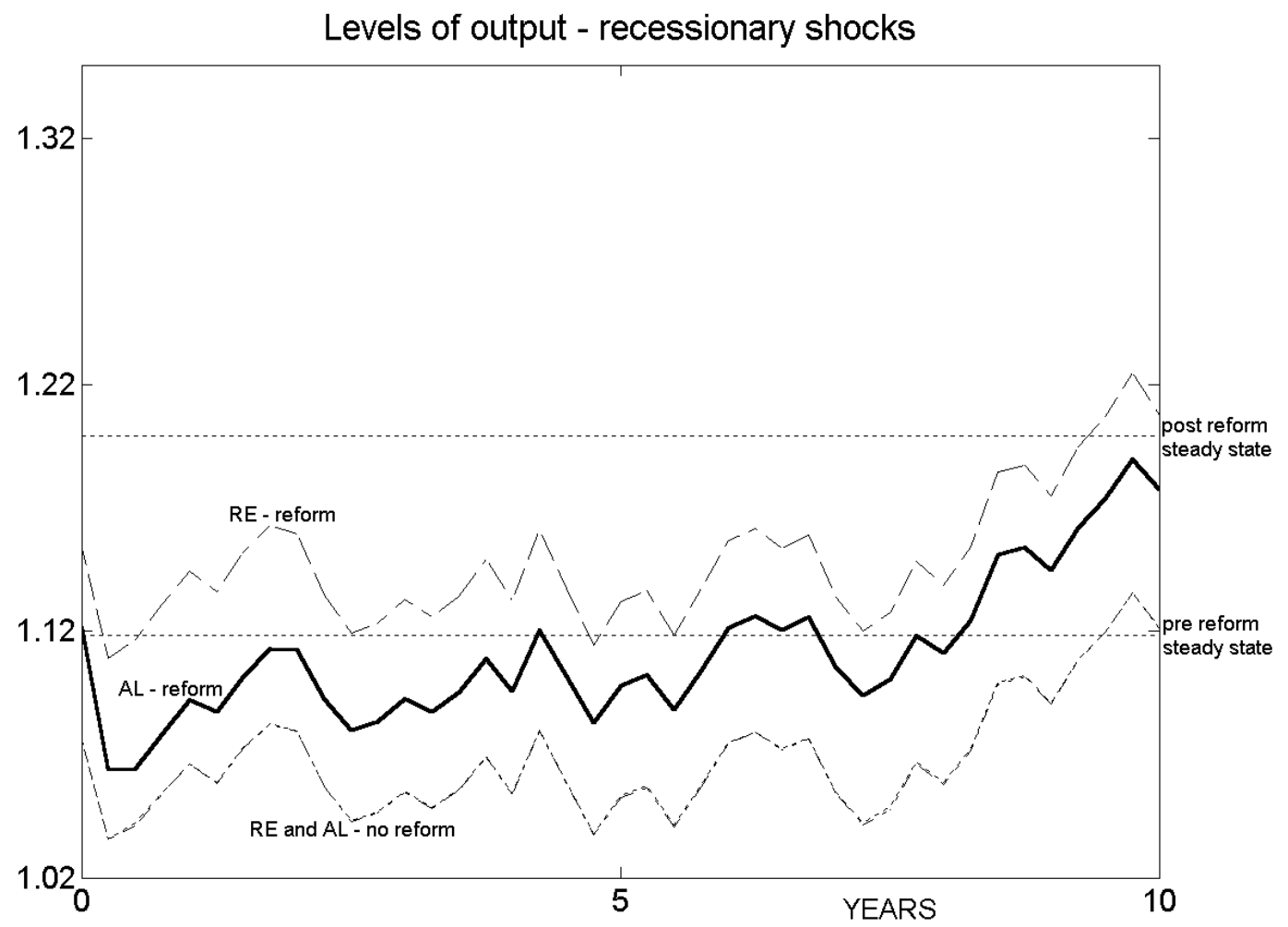

Figure 6: 


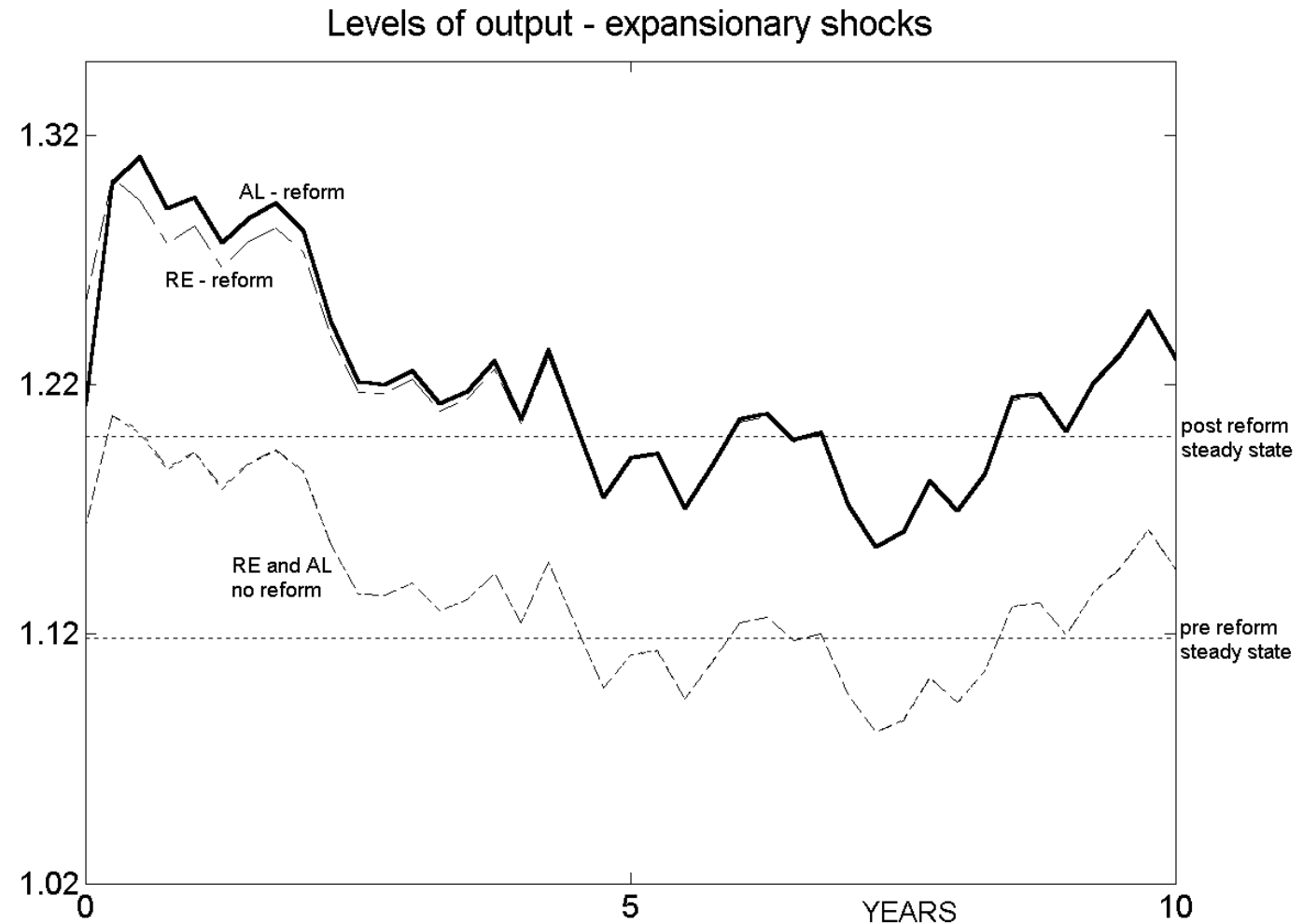

Figure 7: 